strual period eight years before presentation, this seems somewhat tenuous and the authors themselves suggest endometriosis as an alternative underlying factor.

A ceroid granuloma of the female peritoneum was described by White and Chan, ${ }^{9}$ who suggested that it represented an involutional phenomenon in a case of ectopic decidual change involving the pelvic peritoneum in a pregnant woman. They surmised that decidual cells may be engulfed by macrophages and provide the substrate for ceroid formation. Although no history of endometriosis was given, it is interesting to note that pre-existing peritoneal endometriosis may undergo decidual change during pregnancy. Ishizaki ${ }^{4}$ also postulated that degeneration and necrosis in trophoblastic and decidual cells in placentas may result in ceroid production. In our second case the lesions occurred in the setting of established endometriosis, and in the ovary the sheets of pigment-laden macrophages merged with an obvious deposit of endometriosis.

Case 3 did not appear to be related to endometriosis but clearly the presence of a necrotic, poorly differentiated, endometrial adenocarcinoma would provide ample substrate for ceroid production in the form of cellular debris. It is interesting that the granulomas developed in the cervix even though the tumour was located in the uterine fundus. The reason for this is unclear.

The lesions we have described bear many similarities to the necrotic pseudoxanthomatous nodules of ovary and peritoneum described by Clement et al, ${ }^{10}$ which they ascribed to an unusual end stage manifestation of endometriosis. The cases presented here, however, lacked the well circumscribed nodularity, central necrosis and hyalinised collagen described by Clement et al. Moreover, the granulomas in our series were intimately related to, or merged with, endometriotic foci while the necrotic nodules predominantly occurred elsewhere in the peritoneum close to endometriotic foci. The presence of both ceroid and haemosiderin within sheets of macrophages, the age distribution (older women between 40 and 72 years of age in their series) and the association with endometriosis are similar, and suggest that the two lesions represent different stages in the evolution of endometriosis.

Ceroid granulomas may mimic other lesions, both macroscopically and histologically, depending on their location. In the cervix, endometrium and ovary they can be distinguished from malakoplakia by the absence of MichaelisGuttman bodies, from decidual change by the clinical setting and by morphological and staining characteristics, and from endometriosis by the lack of glands surrounded by endometrial stroma. Endometrial stromal foam cells are present in endometrial hyperplasia or carcinoma and lack the staining profile of ceroid. Infections (including mycobacteria) should be considered and further stains including ZiehlNeelsen performed if clinically warranted. In the peritoneum the differential diagnoses include malakoplakia, ectopic decidual reaction, infection, necrotic pseudoxanthomatous nodules and peritoneal melanosis, whether benign or associated with malignant melanoma.

We are grateful to Dr Kevin Bendall for referring case 2.

1 Lillie RD, Fullmer HM. In: Histopathologic, technic and practical histochemistry. 4th edn. New York: McGraw Hill, 1976:519-21.

2 Bancroft JD, Stevens A (eds). In: Theory and practice of histological techniques. 2nd edn. Edinburgh: Churchill Livingstone, 1983:250-2.

3 Amazon K, Rywlin AM. Ceroid granulomas of the gall bladder. Am f Clin Pathol 1980;73:123-7.

4 Ishizaki $Y$. Ceroid in the placenta. With special reference to meconium staining thereof. Am f Obstet Gynecol 1960;80: meconium

5 Al-Nafussi AI, Hughes D, Rebello G. Ceroid granuloma of the uterine cervix. Histopathology 1992;21:282-4.

6 Shintaku M, Sasaki M, Baba Y. Ceroid-containing histiocytic granuloma of the endometrium. Histopathology 1991;18:169-72.

7 Reagan JW. Ceroid pigment in the human ovary. $A m \mathcal{f}$ Obstet Gynecol 1950;59:433-6.

8 Clement PB. Pathology of endometriosis. Pathol Annu 1990; 25:245-83.

9 White J, Chan Y-F. Lipofuscinosis peritonei associated with pregnancy-related ectopic decidua. Histopathology 1994; 25:83-5.

10 Clement PB, Young RH, Scully RE. Necrotic pseudoxanthomatous nodules of ovary and peritoneum in enxanthomatous nodules of ovary and peritoneum
dometriosis. Am $\mathcal{F}$ Surg Pathol 1988;12:390-7.

11 Thomas W Jr, Sadegheih B, Fresco R, Rubenstone AI, Stepto RC, Carasso B. Malacoplakia of the endometrium a probable cause of postmenopausal bleeding. Am $\mathfrak{f}$ Clin Pathol 1978;69:5637-41.

12 Fechner RE, Bossart MI, Spjut HJ. Ultrastructure of endometrial stromal foam cells. Am $\mathcal{f}$ Clin Pathol 1979;72: 628-33.

\title{
Pseudoangiosarcomatous carcinoma of the genitourinary tract
}

\author{
Department of \\ Histopathology, \\ Bolton General \\ Hospital, \\ Bolton \\ Correspondence to: \\ Dr M A Pitt, \\ Department of \\ Histopathology, \\ Royal Preston Hospital, \\ Sharoe Green Lane North, \\ Fulwood, Preston PR2 4HT \\ Accepted for publication \\ 30 May 1995
}

M A Pitt, G Morphopoulos, S Wells, D L Bisset

\author{
Abstract \\ Two cases of pseudoangiosarcomatous \\ carcinoma of the genitourinary tract, aris- \\ ing in the vulva in one and the bladder in \\ the other, are presented. In case 1 , an 84 \\ year old woman, the vulvectomy specimen \\ contained an irregular ulcerated tumour, \\ infiltrating the left labia and extending into \\ the clitoris. In case 2 , a 59 year old woman, \\ the excised bladder showed diffuse thick-
}


ening of its wall by infiltrating haemorrhagic tumour. Both tumours showed focal keratinisation. This, in association with the presence of atypical squamous epithelium, immunohistochemistry and ultrastructural analysis, led to a diagnosis of pseudosarcomatous carcinoma in both cases. Pseudoangiosarcomatous carcinoma should be considered in the differential diagnosis of malignant angiomatoid tumours, particularly those that arise at sites, like the genitourinary tract, where angiosarcoma is rare.

( $(\mathcal{C}$ Clin Pathol 1995;48:1059-1061)

Keywords: Pseudoangiosarcomatous carcinoma, sarcoma, vulva, bladder, immunohistochemistry.

Carcinomas from varying sites, including the genitourinary tract, may show sarcomatous morphological features, most commonly with a spindle cell pattern which mimics fibro-

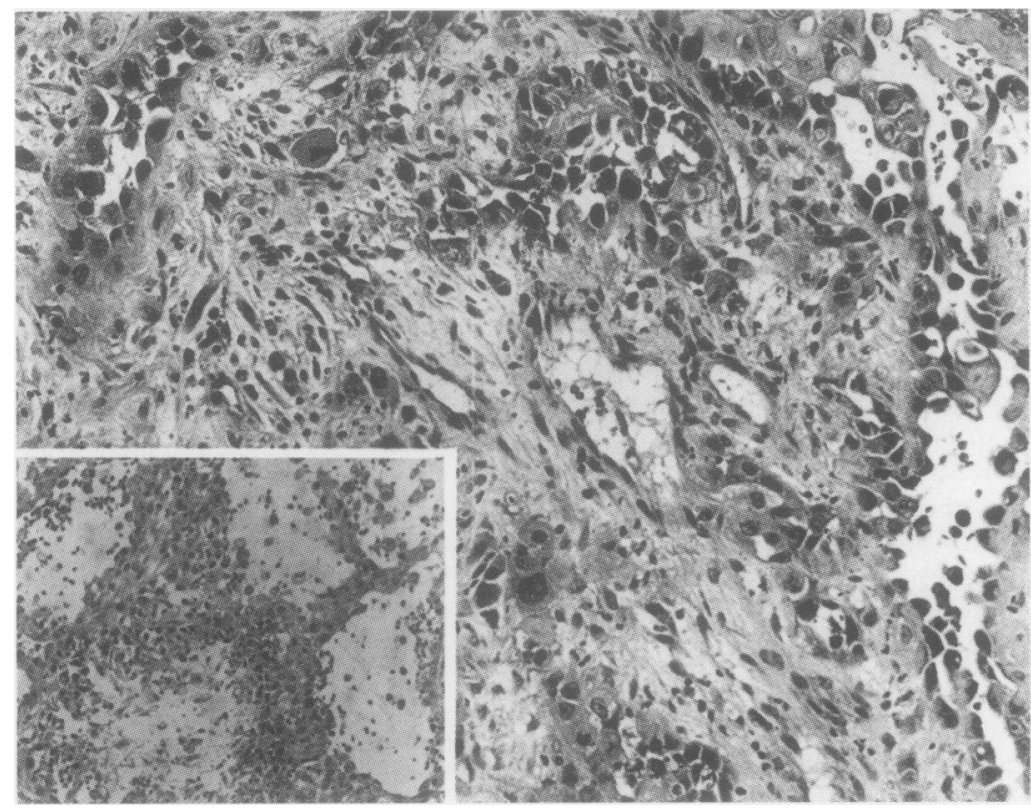

Figure 1 Vulval tumour showing vascular-like channels lined by plump epithelioid cells. Inset: tumour with cystic spaces and myxoid areas.

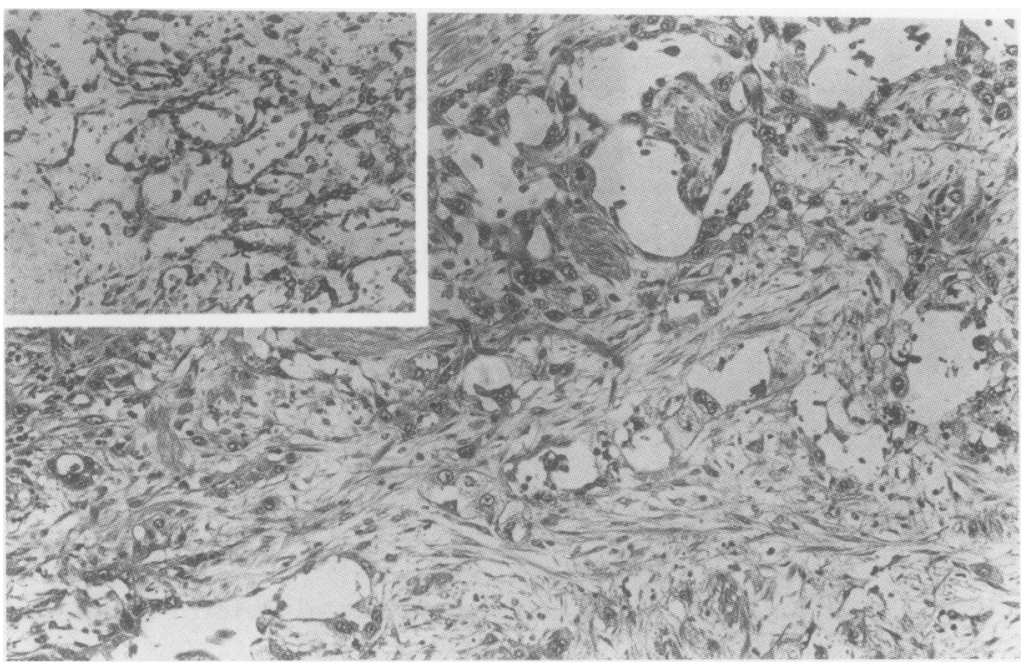

Figure 2 Bladder tumour with irregular anastomosing channels and spaces giving a pseudoangiosarcomatous appearance. Inset: Cam $5 \cdot 2$ immunostaining of tumour cells lining vascular-like channels. sarcoma or leiomyosarcoma. ${ }^{12}$ More recently, examples with a pseudoangiosarcomatous appearance have been reported. These have been described in the breast, skin, thyroid, and lung. ${ }^{3-5}$ Here, we report two cases arising in the vulva and bladder which were distinguished from angiosarcoma, an exceedingly rare neoplasm at these sites, using immunohistochemistry.

\section{Case reports}

CASE ONE

An 84 year woman presented with symptoms suggestive of a urinary tract infection. On examination, the patient was found to have a fungating tumour affecting the vulva and clitoris. A radical vulvectomy was performed, following which she developed a lymph fistula. Three months later, a large fluctuant perineal swelling, thought to be an abscess, was noted, drained and biopsied. The patient's condition deteriorated and she died two weeks later. A postmortem examination was not performed.

\section{Pathological findings}

On examination, the radical vulvectomy specimen showed an irregular ulcerated tumour measuring $4 \times 3 \times 3 \mathrm{~cm}$, infiltrating the left labia and extending into the clitoris. Enlarged lymph nodes were present in the left inguinal area. The subsequent perineal biopsy specimen consisted of skin and pieces of grey tissue up to $1.2 \mathrm{~cm}$ in size.

Microscopically, tumour was present in both specimens and was composed of sheets of large epithelioid malignant cells with occasional small foci of keratinisation. No atypical overlying or adjacent squamous epithelium was seen. However, in the recurrent perineal tumour there were irregular anastomosing vascular-like channels and clefts lined by plump epithelioid cells, giving an appearance strongly reminiscent of epithelioid angiosarcoma (fig 1). Areas with cystic spaces and myxoid change containing alcian blue positive material were also present. In adjacent tumour a more spindle cell sarcomatoid appearance was seen.

Immunohistochemistry on the recurrent pseudoangiosarcomatous tumour was negative for factor VIII (diluted 1 in 400; Dako, High Wycombe, UK), QBEND10 (diluted 1 in 200; Unipath, Basingstoke, UK), JC70 (diluted 1 in 100; Dako), and $S 100$ protein (diluted 1 in 800; Dako), but was positive for Cam $5 \cdot 2$ (diluted 1 in 20; Becton Dickinson, Ontario, Canada) and AE1/3 (diluted 1 in 1000; Unipath).

Two of the eight lymph nodes examined contained metastatic tumour without sarcomatoid features.

\section{CASE TWO}

A 59 year old woman presented with haematuria. On cystoscopy, she was found to have a large tumour, biopsy specimens from which showed necrotic invasive transitional cell carcinoma, WHO grade III, infiltrating the muscle wall. An anterior exenteration was performed. 


\section{Pathological findings}

The bladder showed diffuse thickening of most of its wall by infiltrating haemorrhagic tumour. Microscopically, the tumour was predominantly a typical high grade transitional cell carcinoma showing focal keratinisation. In the deeper aspect there was a spindle cell and pseudoangiosarcomatous pattern similar to that seen in case 1, with cystic and slit-like spaces lined by tumour cells (fig 2 ). These were also negative for factor VIII, QBEND10, JC70, and $S 100$ protein, but positive for Cam $5 \cdot 2$ and $A E 1 / 3$ (fig 2).

Lymph nodes examined contained metastatic tumour which also had a pseudoangiosarcomatous pattern.

\section{Discussion}

Sarcomas of the vulva and bladder are rare and are predominantly leiomyosarcomas and malignant fibrous histiocytomas. ${ }^{67}$ Angiosarcomas are exceedingly rare with only occasional cases reported. ${ }^{6}$ While examples of so called spindle cell or pseudosarcomatous carcinoma of the female genital tract and bladder have been described, ${ }^{12}$ no case of pseudoangiosarcomatous carcinoma has, to our knowledge, been reported at these sites. Banerjee et $a l^{3}$ studied seven cases from skin, breast and lung, four of which were originally diagnosed as angiosarcoma, and Nappi et $a l^{45}$ reported a small series from the skin and lung. The correct diagnosis was established by a combination of a careful search for focal keratinisation and atypical squamous epithelium, immunohistochemistry and ultrastructural analysis. In our cases the tumours had similar morphological features to those described by Banerjee et al and Nappi et al, the diagnoses being confirmed by the presence of focal keratinisation and a vascular marker negative, cytokeratin positive immunophenotype.

It has been suggested that acantholysis is the underlying pathogenic mechanism, ${ }^{3}$ possibly as a consequence of changes in adhesion molecule expression by the tumour cells. There is evidence of reduced E-cadherin expression in nonneoplastic acantholytic disorders of the skin ${ }^{8}$ and a study of adhesion molecule expression in these sarcomatoid tumours would be of interest.

Pseudoangiosarcomatous carcinoma seems to behave in an aggressive manner reflecting the high grade, poorly differentiated nature of the carcinoma. ${ }^{3-5}$ Angiosarcomas of the vulva may, however, behave in a more indolent fashion with recurrences and late metastases by the haematogenous rather than the lymphatic route. ${ }^{6}$

In conclusion, pseudoangiosarcomatous carcinoma should be considered in the differential diagnosis of malignant angiomatoid tumours, particularly those that arise at sites, like the genitourinary tract, where angiosarcoma is rare. Adequate sampling with careful examination for keratinisation, atypical squamous epithelium and areas of differentiated carcinoma is advised and immunohistochemistry and possibly electron microscopy performed.

1 Steeper TA, Piscioli F, Rosai J. Squamous cell carcinoma with sarcoma-like stroma of the female genital tract. Cancer 1983;52:890-8.

2 Torenbeck R, Blomjous CEM, de Bruin PC, Newling DWW, Meijer CJLM. Sarcomatoid carcinoma of the urinary bladder. Clinicopathologic analysis of 18 cases with immunohistochemical and electron microscopy findings. $\mathrm{Am}$ munohistochemical and electror

3 Banerjee SS, Eyden BP, Wells S, McWilliam LJ, Harris M. Pseudoangiosarcomatous carcinoma: A clinicopathological study of seven cases. Histopathology 1992;21:13-23.

4 Nappi O, Wick MR, Pettinato G, Ghiselli RW, Swanson PE. Pseudovascular adenoid squamous cell carcinoma of the skin. A neoplasm that may be mistaken for angiosarcoma. Am $f$ Surg Pathol 1992;16:429-38.

5 Nappi O, Swanson PE, Wick MR. Pseudovascular adenoid squamous cell carcinoma of the lung: Clinicopathologic study of three cases and comparison with true pleuropulmonary angiosarcoma. Hum Pathol 1994;25:373-8.

6 Davos I, Abell MR. Soft tissue sarcomas of the vulva. Gynecol Oncol 1976;4:70-86.

7 Swartz DA, Johnson DE, Ayala AG, Watkins DL. Bladder leiomyosarcoma. A review of 10 cases with five year follow up. $₹$ Urol 1985;133:200-2.

8 Burge SM, Schomberg KH. Adhesion molecules and related proteins in Dariers disease and Hailey-Hailey disease. $\mathrm{Br}$ $\mathcal{F}$ Dermatol 1992;127:335-43.

\section{Elevated serum $\alpha$-fetoprotein in a patient with undifferentiated carcinoma of the gall bladder}

\author{
Department of \\ Pathology, \\ University of Hong \\ Kong, \\ Queen Mary Hospital \\ Compound. \\ Pokfulam Road, \\ Hong Kong \\ W K Ng \\ Department of \\ Pathology, Ruttonjee \\ Hospital, Hong Kong \\ W F Ng \\ Correspondence to: \\ $\mathrm{Dr} W \mathrm{~K} \mathrm{Ng}$ \\ Accepted for publication \\ 24 April 1995
}

W K Ng, W F Ng

\begin{abstract}
An uncommon case of undifferentiated carcinoma of the gall bladder in a 65 year old Chinese man, who presented with an increased serum $\alpha$-fetoprotein concentration, is reported. Histologically, the tumour had a primitive appearance and was composed of a pavement-like array of poorly differentiated columnar/polygonal
\end{abstract}

cells. Alpha-fetoprotein was demonstrated in some of the tumour cells using an immunoperoxidase technique. Alpha-fetoprotein secretion in this instance may have occurred because the gall bladder and the liver are of similar embryological origin. Alpha-fetoprotein may also be related to the resurgent expression of oncofetal antigens. This tumour may represent an- 